\title{
Correlation of pasting behaviors with total phenolic compounds and starch digestibility of indigenous pigmented rice grown in upper Northern Thailand
}

\author{
Jirapa Pongjanta ${ }^{1}$, Ni-orn Chomsri ${ }^{1}$ and Sawit Meechoui ${ }^{2}$ \\ ${ }^{1}$ Department of Food Science, ${ }^{2}$ Department of Agronomy, Agricultural Technology Research \\ Institute, Rajamangala University of Technology Lanna, Lampang, 5200 Thailand \\ *Corresponding Author: Dr. Jirapa Pongjanta, Department of Food Science. Agricultural \\ Technology Research Institute, Rajamangala University of Technology Lanna, Muang \\ Lampang, 5200 Thailand
}

Submission Date: October 11, 2015; Acceptance Date: March 6, 2016; Publication Date: March 9, 2016

\begin{abstract}
Background: Thailand has one of the most important rice genetic resources with white, light brown, brown, red, and purple rice bran colors. The latter forms are believed to have the potential for health benefits due to their phenolic content. Recently researchers have indicated that starch digestive enzymes, including salivary and pancreatic $\alpha$-amylases and $\alpha$ glucosidases, can be inhibited by phenolic compounds. Although pasting properties of rice flour are key determinants of quality significantly impacting the final product texture, there is no in-depth study on their correlation with phenolic compound and starch digestibility.
\end{abstract}

Methods: Rice flour from twelve varieties, three from each of five bran colors (white, brown, red, and purple), were evaluated for pasting properties (RVA-3D), total phenolic compounds, amylose content, resistant starch and estimated glycemic index. Simple correlation coefficients were calculated for the relationships between pasting properties (final viscosity, breakdown, setback and pasting temperature) and total phenolic compounds, resistant starch and estimated glycemic index.

Results: Within each rice variety, red and purple pigmented flours had higher total phenolic compounds (TPC) and more resistant starch than that of white flours. The TPC and resistant starch content of the flours ranged between $7.83-47.3 \mathrm{mg} / \mathrm{L}$ and $2.44-10.50 \%$ respectively, and producing 60-80 of estimated glycemic index. Viscosity behavior showed that pigmented with low amylose rice had lower viscosity temperature than that of pigmented with high amylose rice flour, but higher in peak viscosity. Correlation coefficients of pasting temperature, final viscosity, break down and setback with TCP was observed to be inversely related to glycemic index. However, it was positively correlated to the resistant starch and amylose content. 
Conclusions: Pigmented rice flour is a better source of TPC and resistant starch, which in turn provides low glycemic index. This could help reduce the onset of type 2 diabetes and other related chronic diseases. In addition, this study provides impact of pasting behavior TPC- resistant starch of rice flour relationships, which have important implication for utilization in food industry.

Keywords: total phenolic compounds, amylose content, resistant starch, glycemic index

\section{BACKGROUND:}

Thailand is a major rice producing and export country with the export volume of about 5-6 million tons per year. Thailand also has one of the most important rice genetic resources with white, light brown, brown, red, and purple rice bran colors. Pigmented rice, which belongs to the special rice varieties, contains pigments in the aleurone layer composed of a mixture of anthocyanins [1]. Its grain color ranges from various shades of red and purple to black. Pigmented rice was reported to have a health-promoting potential due to its substantial antioxidant content which inhibited the formation or reduced the concentrations of reactive cell-damaging free radicals [2, 3, 4],such as protecting the body tissue from oxidative damage. The consumption of this rice is associated with reduced risk of developing chronic diseases, for instance, cardiovascular disease and diabetes [5, 6]. Recently researchers indicate that starch digestive enzymes, including salivary and pancreatic $\alpha$-amylases and $\alpha$ glucosidases, can be inhibited by phenolic compounds [7].

\section{INTRODUCTION:}

Rice (Oryza sativa L.) is the most important cereal crop and the stable food of over half the world's population. The majority of rice varieties grown in Thailand are long grain. In Thailand, rice varieties are divided into 4 types according to custom and usage, such as waxy rice, low, medium and high amylose rice. More than 5,000 rice varieties are known within the country. The rice most suitably grown in each part of the country varies due to environmental differences. Rice varieties commonly used in commercial rice flour production in Thailand are waxy and high amylose rice that involve of pigmented rice. In 2014-2015, Thailand produced 38.80 million tons of paddy rice and exported 9 million tons. The use of rice as a food ingredient has also increased by $3.7 \%$ due to the rising popularity and availability of snacks, frozen dish, rice pudding, package mixes and beverage. More research on rice functionality, physical and chemical properties is needed in order to meet the food industry's demand for low-fat, hypoallergenic and nutritious food ingredient. Colored rice was reported to have a health-promoting potential due to its substantial antioxidant content which inhibits the formation or reduces the concentrations of reactive cell-damaging free radicals $[8,9]$, thus protecting the body tissue from oxidative damage [10].

Furthermore, the Rapid Viscosity Analysis (RVA) for pasting properties of flour play an important role within amylose content for estimating the eating qualities, cooking and processing quality of rice [11]. However, there is lack information on indigenous pigmented rice properties grown in upper Northern Thailand, relating varieties to their best matching applications. There are many pigmented varieties of rice grown in these areas which have not been thoroughly investigated in which they might prove beneficial for functional food ingredient. Thus, the purpose of this paper was to determine the physicochemical properties of twelve varieties of the indigenous rice flour samples. The correlations of pasting behaviors 
with phenolic compounds and starch digestibility of the rice flour with difference amylose content and color of pigmented were investigated.

\section{MATERIALS AND METHODS:}

Rice material: Twelve varieties of rice grain with varying amylose content (low, medium and high) and different pigmented, three from each of five bran colors, white (Tunyasirin; TYSR, Hompangmapa; HPMP and Jaoloy; JL), brown (116 R-258, Langsawbaa; LSB and Buepator; BPT), red (Dayuneanae; DYNN, Khowhoaw; KH and Dangmaejang; DMJ) and purple (Khaokum; KK, URCN-2001 and Homlanna; HLN), were purchased from the Maehongson Rice Research Center and Agricultural Technology Research Institute, Rajamangala University of Technology Lanna . Lampang province, Thailand. The rice grains were de-husked to polish rice by a laboratory rice mill (Satake, Australia) and further made into rice flour by a cyclotec sample mill (Foss North America). Resistant starch assay kit (Megazyme) was obtained from Megasyme International Ireland Ltd., IRELAND. Pepsin (EC 3.4.23.1; 2,980 unit/mg), $\alpha$ - amylase (E.C. 3.2.1.1; Type VI-B from hog pancreas; 20.4 unit/mg) and amyloglucosidase (A-3042; 69.65 unit/mg, from aspergillus niger), Glucose (GO) assay kit (GAGO-20) were purchased from Sigma Chemical Company, USA. All chemicals used in the analysis of rice flour samples were of AR grade or equivalent.

Analysis of color value: The color value of the 12 rice flour samples were measured by a colorimeter (Minolta, CM-3500, Japan) using the CIELAB system namely, L* (lightness), $+\mathrm{a}^{*}$ (redness), $-\mathrm{a}^{*}$ (greenness), $+\mathrm{b}^{*}$ (yellowness), and $-\mathrm{b}^{*}$ (blueness). The colorimetric measurements were performed three times for each sample.

Analysis of pasting behaviors: The pasting properties of the twelve rice flour samples were determined with a rapid visco analyser (Newport Scientific, Australia). Rice flour (3 g on a d.b.) was poured into distilled water $(25 \mathrm{~mL})$ in a canister and mixed thoroughly. The mixture was stirred at $960 \mathrm{rpm}$ for 10 second and then stirred at $160 \mathrm{rpm}$. The mixture temperature was first maintained at $50^{\circ} \mathrm{C}$ for $1.5 \mathrm{~min}$ and then raised to $95^{\circ} \mathrm{C}$ at a rate of $12^{\circ} \mathrm{C} / \mathrm{min}$. After that, the temperature was maintained at $95{ }^{\circ} \mathrm{C}$ for $2.5 \mathrm{~min}$; this was followed by a cooling down period to $50^{\circ} \mathrm{C}$ with a cooling rate of $12^{\circ} \mathrm{C} / \mathrm{min}$ and was maintained at $50^{\circ} \mathrm{C}$ for 2.1 min. Each test was made in triplicate. A plot of pasting viscosity in an arbitrary RVA unit (RVU) versus time was used to determine the peak viscosity, temperature at peak viscosity, breakdown viscosity, final viscosity and setback viscosity [12].

Analysis of amylose content: The amylose content of the twelve rice flour samples was measured using the procedure of Juliano [13] with minor modification. Rice flour (100 mg) was mixed with $1 \mathrm{~mL}$ of $95 \%$ ethanol and $9 \mathrm{~mL}$ of $1.0 \mathrm{~mol} / \mathrm{L} \mathrm{NaOH}$, and incubated at room temperature overnight to gelatinize the starch. The samples were diluted to $100 \mathrm{~mL}$ with distilled water. A $5 \mathrm{~mL}$ aliquot of this suspension was mixed with $1 \mathrm{~mL}$ glacial acetic acid (1 $\mathrm{mol} / \mathrm{L})$ and $1.5 \mathrm{~mL}$ iodine solution $(0.2 \%$ iodine and $2 \%$ potassium iodide), and the volume was adjusted to $100 \mathrm{~mL}$ with distilled water. The samples were incubated at room temperature for $20 \mathrm{~min}$, and then the absorbance at $620 \mathrm{~nm}$ was measured. The amylose content of different accessions was obtained using a potato amylose standard curve [14]. 
Analysis of total phenolic compounds: Total phenolic compounds of the twelve rice flour samples were assayed using the Folin-Ciocalteau method [8]. Rice flour $(1 \mathrm{~g})$ of each variety was extracted with $10 \mathrm{~mL}$ of a methanol for 30minat room temperature. The mixture was centrifuged at $2500 \mathrm{~g}$ for $15 \mathrm{~min}$ and $100 \mu \mathrm{L}$ of the supernatant was pipetted into test tube and $3.9 \mathrm{~mL}$ of distilled water and $100 \mu \mathrm{L}$ of Folin-Ciocalteau reagent were added. After 8 min incubation at room temperature, $2 \mathrm{~mL}$ of sodium carbonate solution $(75 \mathrm{~g} / \mathrm{L})$ was added. The mixture was incubated for $15 \mathrm{~min}$ at $50^{\circ} \mathrm{C}$ and cooled quickly in an ice-water bath. The absorbance at $765 \mathrm{~nm}$ was read within $15 \mathrm{~min}$ by spectrophotometer. The standard curve was made using $0,50,100,150,200,250,300$ and $350 \mathrm{mg} / \mathrm{L}$ of gallic acid. The obtained regression equation was $\mathrm{y}=0.002 \mathrm{x},\left(\mathrm{R}^{2}=0.999\right)$.

Analysis of resistant starch content: Resistant starch (RS) was determined using a Megazyme Resistant Starch kit [15]. The samples were incubated in a shaking water bath with pancreatic $\alpha$-amylase and amyloglucosidase for $16 \mathrm{hr}$ at $37^{\circ} \mathrm{C}$ to reduce digestible starch to glucose. The reaction was terminated with $4 \mathrm{ml}$ ethanol and the indigested RS III was recovered by centrifugation $(5000 \mathrm{~g}, 10 \mathrm{~min})$. The supernatant was decanted and washed with $50 \%$ ethanol for two times (digested starch). The indigested RS III was solubilized in $2 \mathrm{~mL}$ of $2 \mathrm{M} \mathrm{KOH}$ in an ice bath, neutralized with $8 \mathrm{ml}$ sodium acetate $(1.2 \mathrm{M})$ and the RS hydrolyzed to glucose with of AMG $\left(0.1 \mathrm{ml}, 3300 \mathrm{Uml}^{-1}, 50^{\circ} \mathrm{C}\right)$. The glucose oxidase/peroxidase reaction was used to measure glucose released from the digested starch and resistant starch. Absorbance was read $(510 \mathrm{~nm})$ after a $20 \mathrm{~min}$ incubation period at $50^{\circ} \mathrm{C}$. Resistant starch and digested starch were calculated as glucose $\times 0.9$.

Analysis of estimated glycemic index: In vitro starch hydrolysis and estimate glycemic index (EGI) were determined according to Goni et al. [16]. Each rice flour sample (50 mg, $\mathrm{db}$ ) was cooked in $5.0 \mathrm{~mL}$ of water for $30 \mathrm{~min}$ and incubated with $10 \mathrm{~mL}$ of pepsin solution prepared in $\mathrm{HCl}-\mathrm{KCl}$ buffer $\mathrm{pH} 1.5$ at $40^{\circ} \mathrm{C}$ for $1 \mathrm{~h}$ in a shaking water bath. The volume of the samples was made to $25 \mathrm{~mL}$ using Tris-Maleate buffer ( $\mathrm{pH}$ 6.9). Reaction was started by adding $\alpha$-amylase (2.6 units in $5 \mathrm{~mL}$ of buffer $\mathrm{pH}$ 6.9) and the samples were incubated at $37^{\circ} \mathrm{C}$ in a shaking water bath. One $\mathrm{mL}$ of the sample aliquot was collected at intervals of 30 $\min$ for $3 \mathrm{~h}$. The enzyme activity in these aliquots was inactivated by heating at $100^{\circ} \mathrm{C}$ for 5 min and refrigerated until the end of the incubation period. To these aliquots, $3 \mathrm{~mL}$ of $0.4 \mathrm{M}$ sodium acetate buffer ( $\mathrm{pH} 4.75)$ and $60 \mu \mathrm{L}$ amyloglucosidase were added to hydrolyze the digested starch to glucose. The samples were incubated at $60{ }^{\circ} \mathrm{C}$ for $45 \mathrm{~min}$. The glucose content in each aliquot was estimated using glucose oxidase peroxidase kit. Glucose was converted into starch by multiplying with 0.9. All the experiments were conducted with triplicates in each analysis. The kinetics of starch digestion was estimated by non-linear first order equation established as an equation:

$$
A U C=C_{\alpha}\left(t_{f}-t_{0}\right)-\frac{C_{\alpha}}{k}\left(1-e^{-k\left(t_{f}-t_{0}\right.}\right)
$$

Where, $C_{\propto}$ corresponds to the concentration at equilibrium $\left(t_{180}\right)$. $t_{\mathrm{f}}$ is the final time (180 $\mathrm{min}), t_{0}$ is the initial time ( $\left.0 \mathrm{~min}\right)$, and $k$ is the kinetic constant. A hydrolysis index (HI) was calculated by comparison with the AUC of a reference food (white bread). The hydrolysis index (HI) was calculated as the percentage of total glucose released from the samples as 
compared to that released from white bread (0-180 min). The estimated glycemic index of the samples was estimated according to the equation: $\mathrm{GI}=(39.71+0.549) \times \mathrm{HI}[17]$.

Statistical analyses: All the analyses data were carried out in triplicate and expressed as mean and standard deviation. Data were statistically analyzed by analysis of variance (ANOVA) and significant differences of the means were separated by Duncan's Multiple Range test $(p<0.05)$ procedure. The Pearson correlation analysis was performed.

\section{RESULTS:}

Color value; The results for the color value and appearance of the twelve rice flour samples were given in Table 1 and Fig 1 . The color parameters $\left(\mathrm{L}^{*}, a^{*}\right.$ and $\left.b^{*}\right)$ of the rice flour samples were significant difference $(\mathrm{p}<0.05)$ among the twelve rice varieties. $\mathrm{L}^{*}$ values, which expressed the brightness, were in the range of 55.12-91.55. Whiteness was more prominent in JL rice flour followed by HPMP and TYSR rice flour. The HLN, URCN and KK rice flour exhibited much lower $\mathrm{L}^{*}$ values due to the purple pigmented external layers of the kernels that existed even after polishing and grinding. In addition, the brown and red pigmented rice flour had $\mathrm{L}^{*}$ value in the range of 88.92-89.12 and 86.8887.88, respectively. The values of $a^{*}$ and $b^{*}$ were in the range of -2.25- 4.28 and 0.14-7.64, respectively. The positive $a^{*}$ values for redness were the highest for the DMJ rice flour sample due to red-dish red colored external layers followed by $\mathrm{KH}, \mathrm{KK}$ and DYNN, respectively. Color appearances of the twelve rice flour samples can be clearly seen in Fig 1. The color of each rice variety had low, medium and high amylase content.

The differences in rice flour color are based on a color covering the outer layer of seed. Thus, the brownish red rice is called red rice while the purplish is called black rice. This pigment remains in the aleurone layer of rice seed, and it is recognized as the mix of anthocyanin compounds [18].

Table 1. The color value and pasting properties ${ }^{*}$ of the twelve rice flour samples with different amylose content and pigmented rice varieties ${ }^{* *}$

\begin{tabular}{|c|c|c|c|c|c|c|c|c|c|}
\hline \multirow{2}{*}{$\begin{array}{l}\text { Rice variety- } \\
\text { Bran color }\end{array}$} & \multicolumn{3}{|c|}{ Color value } & \multirow{2}{*}{$\begin{array}{l}\mathrm{PT} \\
\left({ }^{\circ} \mathrm{C}\right)\end{array}$} & \multicolumn{5}{|c|}{ Pasting viscosity profile (RVU) } \\
\hline & $L$ & $a^{*}$ & $b^{*}$ & & $\mathrm{PV}$ & TV & $\mathrm{BD}$ & FV & SB \\
\hline 1.TYSR-W ${ }^{* * * *}$ & $89.52^{\mathrm{a}^{* *}}$ & $-2.25^{\mathrm{h}}$ & $6.19^{\mathrm{b}}$ & $65.98^{\mathrm{h}}$ & $263.19^{c}$ & $144.97^{\mathrm{d}}$ & $118.22^{\mathrm{c}}$ & $184.33^{\mathrm{f}}$ & $-78.44^{\mathrm{j}}$ \\
\hline 2. HPMP- W & $90.54^{\mathrm{a}}$ & $0.48^{\mathrm{g}}$ & $6.30^{\mathrm{b}}$ & $73.07^{\mathrm{e}}$ & $333.94^{\mathrm{a}}$ & $185.72^{\mathrm{b}}$ & $148.22^{\mathrm{b}}$ & $316.80^{\mathrm{b}}$ & $-17.14^{\mathrm{e}}$ \\
\hline 3. JL $-\mathrm{W}$ & $91.55^{\mathrm{a}}$ & $0.14^{\mathrm{g}}$ & $5.86^{\mathrm{b}}$ & $88.47^{\mathrm{c}}$ & $319.03^{b}$ & $243.33^{\mathrm{a}}$ & $75.69^{\mathrm{g}}$ & $402.72^{\mathrm{a}}$ & $83.70^{\mathrm{b}}$ \\
\hline 4. $116 \mathrm{R}-\mathrm{B}$ & $89.12^{\mathrm{ab}}$ & $2.01^{\mathrm{e}}$ & $7.37^{\mathrm{a}}$ & $70.65^{\mathrm{g}}$ & $333.28^{\mathrm{a}}$ & $179.22^{\mathrm{c}}$ & $154.06^{\mathrm{a}}$ & $279.00^{\mathrm{d}}$ & $-53.92^{\mathrm{h}}$ \\
\hline 5. LSB- B & $88.39^{\mathrm{c}}$ & $1.69^{\mathrm{f}}$ & $6.75^{\mathrm{c}}$ & $91.40^{\mathrm{b}}$ & $219.17^{\mathrm{e}}$ & $105.25^{\mathrm{i}}$ & $113.92^{\mathrm{c}}$ & $186.33^{\mathrm{f}}$ & $-32.83^{\mathrm{g}}$ \\
\hline 6. ВРТ-B & $88.92^{\mathrm{c}}$ & $1.52^{\mathrm{f}}$ & $7.14^{\mathrm{a}}$ & $91.70^{\mathrm{f}}$ & $196.44^{\mathrm{f}}$ & $67.31^{\mathrm{k}}$ & $14.14^{\mathrm{h}}$ & $145.00^{\mathrm{h}}$ & $12.08^{\mathrm{d}}$ \\
\hline 7. DYNN-R & $87.18^{\mathrm{d}}$ & $3.51^{\mathrm{b}}$ & $7.64^{\mathrm{a}}$ & $72.57^{\mathrm{f}}$ & $189.14^{\mathrm{f}}$ & $96.33^{j}$ & $92.80^{\mathrm{f}}$ & $121.72^{\mathrm{i}}$ & $-67.42^{f}$ \\
\hline 8. $\mathrm{KH}-\mathrm{R}$ & $87.18^{\mathrm{d}}$ & $3.80^{\mathrm{f}}$ & $6.96^{\mathrm{a}}$ & $71.80^{f}$ & $230.36^{\mathrm{de}}$ & $120.92^{\mathrm{f}}$ & $109.44^{\mathrm{d}}$ & $154.28^{\mathrm{g}}$ & $-76.08^{h}$ \\
\hline 9. DMJ- R & $86.88^{\mathrm{d}}$ & $4.28^{\mathrm{b}}$ & $6.28^{\mathrm{b}}$ & $94.97^{\mathrm{a}}$ & $142.19^{\mathrm{i}}$ & $114.50^{\mathrm{g}}$ & $27.69^{\mathrm{g}}$ & $222.19^{\mathrm{d}}$ & $80.00^{\mathrm{c}}$ \\
\hline 10. KK-P & $74.61^{\mathrm{f}}$ & $3.54^{\mathrm{a}}$ & $0.14^{\mathrm{d}}$ & $93.17^{\mathrm{ab}}$ & $238.94^{\mathrm{d}}$ & $131.97^{\mathrm{e}}$ & $102.9^{\mathrm{e}}$ & $163.19^{\mathrm{e}}$ & $-71.66^{\mathrm{h}}$ \\
\hline 11.URCN-P & $78.67^{\mathrm{e}}$ & $3.18^{\mathrm{a}}$ & $0.35^{\mathrm{d}}$ & $93.33^{\mathrm{ab}}$ & $149.86^{\mathrm{h}}$ & $112.43^{\mathrm{h}}$ & $39.83^{\mathrm{h}}$ & $246.49^{d}$ & $96.83^{\mathrm{a}}$ \\
\hline 12. HLN-P & $55.12^{\mathrm{g}}$ & $1.55^{\mathrm{f}}$ & $4.14^{\mathrm{c}}$ & $80.35^{\mathrm{d}}$ & $160.58^{\mathrm{g}}$ & $115.36^{\mathrm{g}}$ & $45.22^{\mathrm{h}}$ & $257.97^{\mathrm{c}}$ & $97.39^{\mathrm{a}}$ \\
\hline
\end{tabular}

Average of triplicate measurements of pasting properties by Rapid viscosity analyzer (RVA) 
** Mean values in the same column with different letters were significantly different $(\mathrm{p} \leq 0.05)$

*** $\mathrm{W}=$ White, $\mathrm{B}=$ Brown, $\mathrm{R}=\mathrm{Red}$, and $\mathrm{P}=$ Purple

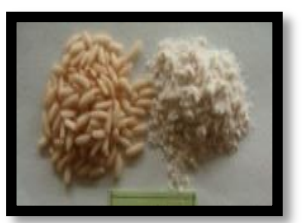

DYNN-R

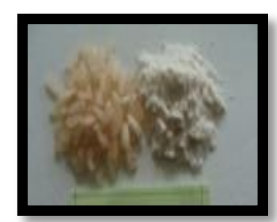

$\mathrm{KH}-\mathrm{R}$

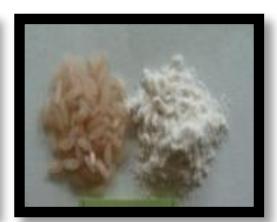

DMJ- R

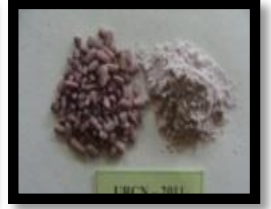

KK-P

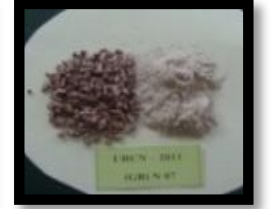

URCN-P

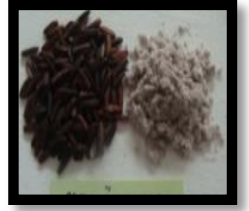

HLN-P

Figure 1. Color appearances of twelve rice flour samples with different amylose content and pigmented of various rice varieties

Pasting properties: The variety of pigmented rice types was clearly affected in the RVA curves of the rice flour samples (Table 1 and Fig. 2). Pasting temperature (PT), peak viscosity (PV), trough viscosity (TV), breakdown (BD), final viscosity (FV) and setback (SB) of the rice flour samples were significantly different $(\mathrm{p}<0.05)$ among rice varieties. The pigmented rice variety was evidently had higher PT than the non-pigmented rice flour samples. DMJ red rice variety exhibited the highest PT $\left(94.97^{\circ} \mathrm{C}\right)$ and the TYSR white waxy rice variety had the lowest $\left(65.98^{\circ} \mathrm{C}\right)$. The higher PT in the waxy pigmented rice flour $\left(83.6^{\circ} \mathrm{C}\right)$ could possibly due to greater resistant to loss of molecular arrangement on cooking [19]. Amylose content also influenced pasting temperature, high amylose content was associated with high pasting temperature and low pasting temperature was prevalent in the variety with lower amylose content. PV value of the waxy non pigmented rice varieties was higher than that of the waxy pigmented rice varieties. However, waxy pigmented rice variety (BPT, KH and KK) showed significantly higher PV. With the exception of TV value, the range of $\mathrm{BD}$, FV and SB values were noticeably higher in the high amylose pigmented than the waxy rice varieties.

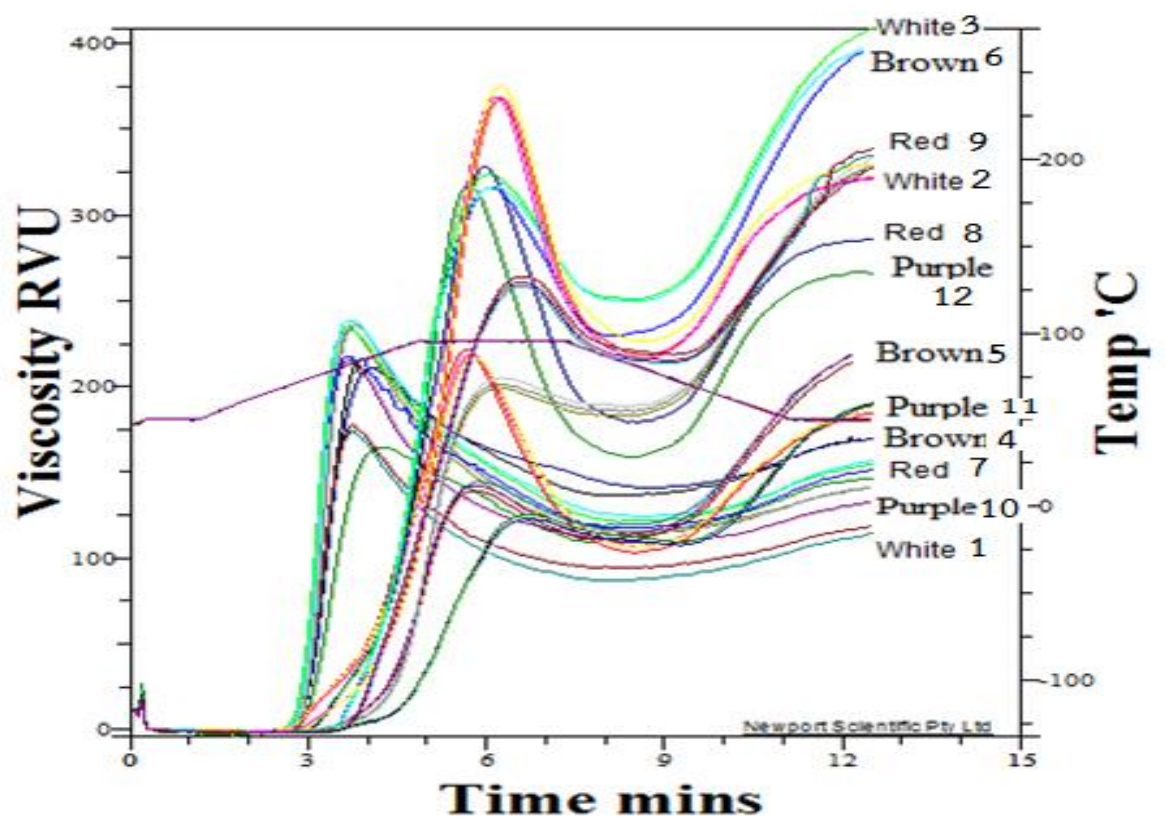

Figure 2. A comparative viscosity curve of twelve rice flour samples with different amylose content and pigmented rice flour as determine by Rapid viscosity analyzer (RVA) 
Amylose content: Amylose content (AC) is important characteristic for predicting rice cooking and processing behaviors. Amylose content among the three varieties of each pigmented rice flour ranged from 1.20 to $28.90 \%$ (Table 2). The pigmented rice variety KK-P showed the lowest amylose content $(1.20 \%)$, while the highest amylose content was recorded in variety JL-W (28.90\%). In white color rice flour had the amylose content ranged from 5.62 to $28.90 \%$. Most pigmented rice flour with brown, red and purple color had amylose contained $5.73-19.30 \%, 5.40$ to $21.92 \%$ and 1.20 to $14.45 \%$, respectively. These values were comparable to that found by Saikia et al. [20] reporting amylose content in pigmented and non-pigmented aromatic rice ranged from 2.2 to $28.80 \%$.

Table 2. Amylose content, total phenolic content, resistant starch and estimated glycemic index of various pigmented rice flour samples*

\begin{tabular}{lllll}
\hline $\begin{array}{l}\text { Rice variety- } \\
\text { Bran color }\end{array}$ & $\begin{array}{l}\text { Amylose } \\
\text { Content } \\
(\%)\end{array}$ & $\begin{array}{l}\text { Total phenolic } \\
\text { content } \\
(\mathrm{mg} / 100 \mathrm{~g} \text { GLA })\end{array}$ & $\begin{array}{l}\text { Resistant } \\
\text { content } \\
(\%)\end{array}$ & $\begin{array}{l}\text { starch } \\
\text { glycemic } \\
\text { index }\end{array}$ \\
\hline 1. TYSR & $5.62 \pm 0.54^{\mathrm{f} * \mathrm{t}}$ & $40.40 \pm 2.18^{\mathrm{e}}$ & $3.06 \pm 0.51^{\mathrm{e}}$ & $83.59 \pm 5.38^{\mathrm{a}}$ \\
W $^{* * * *}$ & & & & \\
2. HPMP-W & $13.19 \pm 1.14^{\mathrm{c}}$ & $48.00 \pm 2.92^{\mathrm{d}}$ & $3.97 \pm 0.67^{\mathrm{c}}$ & $81.87 \pm 0.68^{\mathrm{ab}}$ \\
3. JL-W & $28.90 \pm 2.35^{\mathrm{a}}$ & $67.17 \pm 4.17^{\mathrm{c}}$ & $3.21 \pm 1.02^{\mathrm{e}}$ & $78.92 \pm 4.12^{\mathrm{c}}$ \\
4. 116R -B & $5.73 \pm 0.34^{\mathrm{f}}$ & $80.10 \pm 6.98^{\mathrm{c}}$ & $3.27 \pm 0.28^{\mathrm{e}}$ & $82.79 \pm 2.23^{\mathrm{ab}}$ \\
5. LSB-B & $13.46 \pm 0.46^{\mathrm{c}}$ & $30.20 \pm 4.22^{\mathrm{d}}$ & $4.33 \pm 0.63^{\mathrm{c}}$ & $81.14 \pm 3.51^{\mathrm{b}}$ \\
6. BPT-B & $19.30 \pm 1.12^{\mathrm{a}}$ & $67.26 \pm 2.23^{\mathrm{c}}$ & $6.13 \pm 1.32^{\mathrm{a}}$ & $73.72 \pm 2.68^{\mathrm{e}}$ \\
7. DYNN-R & $5.40 \pm 0.13^{\mathrm{f}}$ & $166.76 \pm 3.47^{\mathrm{b}}$ & $3.20 \pm 1.18^{\mathrm{e}}$ & $80.40 \pm 4.02^{\mathrm{bc}}$ \\
8. KH -R & $7.79 \pm 1.92^{\mathrm{e}}$ & $105.34 \pm 6.04^{\mathrm{b}}$ & $3.61 \pm 0.42^{\mathrm{e}}$ & $79.46 \pm 3.42^{\mathrm{c}}$ \\
9. DMJ- R & $21.92 \pm 2.15^{\mathrm{b}}$ & $128.28 \pm 5.02^{\mathrm{b}}$ & $5.50 \pm 1.18^{\mathrm{b}}$ & $69.64 \pm 0.28^{\mathrm{gh}}$ \\
10. KK-P & $1.20 \pm 0.84^{\mathrm{h}}$ & $127.12 \pm 4.17^{\mathrm{b}}$ & $5.63 \pm 0.42^{\mathrm{b}}$ & $75.20 \pm 3.62^{\mathrm{d}}$ \\
11. URCN-P & $3.60 \pm 0.65^{\mathrm{g}}$ & $228.21 \pm 3.87^{\mathrm{a}}$ & $5.33 \pm 0.25^{\mathrm{b}}$ & $73.83 \pm 1.92^{\mathrm{e}}$ \\
12. HLN-P & $14.45 \pm 1.24^{\mathrm{c}}$ & $238.43 \pm 6.34^{\mathrm{a}}$ & $5.69 \pm 0.47^{\mathrm{ab}}$ & $68.5 \pm 0.284^{\mathrm{f}}$ \\
\hline
\end{tabular}

*Average of triplicate measurements.

${ }^{* *}$ Mean values in the same column with different letters are significantly different $(\mathrm{p} \leq 0.05)$

**** $\mathrm{W}=$ White, $\mathrm{B}=$ Brown, $\mathrm{R}=\mathrm{Red}$, and $\mathrm{P}=$ Purple

Total phenolic compounds: Total phenolic compounds (TPC) of the examined twelve indigenous rice varieties were presented in Table 2 . Significantly differences $(p \leq 0.05)$ were found within the difference color rice varieties, ranging from 40.40 to $248.43 \mathrm{mg} / 100 \mathrm{~g}$ GAE, with TYSR-W $(40.40 \mathrm{mg} / 100 \mathrm{~g})$ rice flour having the lowest value while the highest value was from HLN $-\mathrm{P}(238.43 \mathrm{mg} / 100 \mathrm{~g})$. Purple rice flour samples had the highest phenolic content in the range of 12.12 to $238.43 \mathrm{mg} \mathrm{GAE} / 100 \mathrm{~g}$, followed by red rice flour samples in the range of 166.76 to $128.28 \mathrm{mg}$ GAE/100g. Goffman and Bergman [21] reported the study on pigmented rice that has different phenolic contents. They found that phenolic contents in the white, red and purple rice ranged from 25 to 246, 34 to 424, and 69 to $535 \mathrm{mg} / 100 \mathrm{~g} \mathrm{GAE}$, respectively. In addition, the results obtained by Wang et al., [22], the highest to the lowest phenolic content were obtained in purple rice flour, red rice flour, brown rice flour and white rice flour, respectively. The variation of total phenol 
content in different aromatic rice varieties might be affected by genotype, cultivation techniques, ripening process and environmental variation [23].

Resistant starch content: The resistant starch content of the twelve colored rice flour from indigenous rice varieties were summarized in Table 2. The resistant starch in BPT brown rice flour with medium amylase level was the highest $(6.13 \%)$ but not significant different $(\mathrm{p}>$ 0.05 ) from the three purple brown rice flour samples. The resistant starch contents in the purple rice flour from KK, URCN and HLN varieties were ranged from 5.33 to 5.69\%. The pigmented rice varieties appeared to contain more resistant starch than the non-pigmented rice varieties, a property that can be utilized in the formulation of foods for diabetes or obesity patients. For the result of different amylose content among the 12 indigenous rice varieties, was consistent with previous studies. The high-amylose rice cultivars were found to be relatively high resistant starch in the previous papers of Miller et al. [24], Frei et al. [25] and Alonso et al. [26]. Because of its compact linear structure, the high-amylose starch was more resistant than amylopectin to starch digestion and more prone to form amylose-lipid complexes, a property that could be utilized in the formulation of foods with high RS content [27].

Estimated glycemic index: Estimated glycemic index (EGI) value of different color of rice flour from twelve indigenous rice varieties were shown in Table 2. EGI value ranged from 68.53 to 83.59 with value relatively higher in white and brown rice flour with low amylose content. EGI of white and brown rice flour ranged from 73.72 to 82.79 that could be classified as high glycemic index food. While, purple color rice flour with high amylose content (HLN variety) was shown to have the lowest EGI value (68.53) and followed by red color rice flour (DMJ variety). Compared to other pigmented Thai rice flour, EGI of HLN and DMJ rice flour was lower than that EGI reported for the Sangyod Phatthalung rice flour of $77.1[28]$.

Correlation among indigenous rice flour properties traits: Correlation coefficients of physicochemical properties with pasting temperature, final viscosity, and break down and setback of various pigmented rice flour samples were presented in Table 3. The color $\mathrm{L}^{*}$ had significant and negative association with total phenolic compound $\left(r=0.686^{*}\right)$ and not significant positive correlation with resistant starch content, estimate glycemic index and pasting behaviors. While, $a^{*}$ value had significant and positive association with total phenolic compound $\left(r=0.625^{*}\right)$, which had not significant and positive association with resistant starch content $(r=0.509)$, pasting temperature $(r=0.243)$ and setback $(r=0.152)$. Amylose content had the strongest positive correlations with peak time $(r=0.774 * *)$ followed by tough viscosity $\left(r=0.686^{*}\right)$, setback, peak viscosity, final viscosity and break drown, respectively. In addition, total phenolic compound had significant negative correlation with estimate glycemic index $\left(r=-0.674^{*}\right)$ and peak viscosity $\left(r=-0.688^{*}\right)$, positive correlation with resistant starch content, pasting temperature and peak time, respectively. Resistant starch content had negative correlations with estimate glycemic index $\left(r=-0.846^{* *}\right)$ and positive correlations with setback, peak time and pasting temperature. Estimate glycemic index was observed to be inversely related to setback $\left(r=-0.713^{* *}\right)$, peak time $\left(r=-0.605^{*}\right)$ and pasting temperature. However, it was positively correlated to the peak viscosity and break down. 
Table 3. Correlation among physicochemical properties and pasting behaviors of various non-pigmented and pigmented rice flour samples

\begin{tabular}{llllllll}
\hline & $\mathrm{L}^{*}$ & $a^{*}$ & $b^{*}$ & AMC & TPC & RS & EGI \\
\hline $\mathrm{L}^{*}$ & 1 & & & & & & \\
$a^{*}$ & -.135 & 1 & & & & & \\
$b^{*}$ & .519 & -.433 & 1 & & & & \\
AMC & .264 & -.245 & .389 & 1 & & & \\
TPC & $-.686^{*}$ & $.625^{*}$ & -.500 & -.286 & 1 & & \\
RS & -.465 & .509 & -.515 & .235 & .448 & 1 & \\
EGI & .572 & -.500 & .379 & -.318 & $-.674^{*}$ & $-.846^{* *}$ & 1 \\
PV & .490 & -.550 & .342 & .485 & $-.688^{*}$ & -.241 & .425 \\
TV & .271 & -.476 & .141 & $.686^{*}$ & -.413 & -.077 & .039 \\
BD & .318 & -.403 & .171 & .162 & -.481 & -.052 & .360 \\
FV & .069 & -.245 & -.021 & .361 & -.109 & -.219 & .039 \\
SB & -.307 & .152 & -.265 & .541 & .492 & .486 & $-.713^{* *}$ \\
PT & -.147 & .031 & -.121 & $.774^{* *}$ & .111 & .551 & $-.605^{*}$ \\
Pasting Temp & -.011 & .243 & -.320 & .393 & .205 & .350 & -.457 \\
\hline
\end{tabular}

* Correlation was significant at the 0.05 level (2-tailed).

**Correlation was significant at the 0.01 level (2-tailed).

\section{CONCLUSION:}

The results of this study could serve as baseline information for the consumer who a health concern. White rice is the most-consumed rice but pigmented rice is also considered useful for health in terms of taste, nutrients and anthocyanin content. Pigmented rice flour is a better source of TPC and resistant starch content which in turn, provides low glycemic index. In addition, this study provides the impact of pasting behavior - TPC- resistant starch of rice flour relationships, which have important implication for utilization the indigenous rice flour in food industry applications.

Competing Interests: The authors have no financial interests or conflicts of interest. Authors' Contributions: All authors contributed to this study.

Abbreviations: TYSR-W, Tunyasirin-White; HPMP, Hompangmapa -White; JL-, JaoloyWhite; LSB-B, Langsawbaa-Brown; BPT, Buepator-R; DYNN-R, Dayuneanae- red; KH-R, Khowhoaw; DMJ-R, Dangmaejang-Red; and KK-P, Khaokum -purple; HLN-P HomlannaPurple; PT, Pasting temperature; PV, peak viscosity; TV, trought viscosity; BD, breakdown; FV, final viscosity; SB, setback; TPC, total phenolic compounds

Acknowledgements and Funding: The authors are grateful for the financial supports provided by Agricultural Research Development Agency (ARDA) and National Research Council of Thailand (NRCT). We thank the Agricultural Technology Research Institute, Rajamangala University of Technology Lanna for laboratory support. In addition, we also thank for Dr. Wirat Ampun for his kind on English suggestion in this study. 


\section{REFERENCES:}

1. Yawadio R, Tanimori S, Morita N. Identification of phenolic compounds isolated from pigmented rice and their aldose reductase inhibitory activities. Food Chemistry 2007; 101: 1616-1625.

2. Adom KK, Liu RH. Antioxidant Activity of Grains. Journal of Agricultural and Food Chemistry 2002; 50(21): 6182-6187.

3. Oki, T.; Masuda, M.; Kobayashi, M.; Nishiba, Y.; Furuta, S.; Suda, I. and Sato, T. Polymeric procyanidins as radical-scavenging components in red-hulled rice.Journal Agricultural Food Chemistry 2002; 50: 7524-7529.

4. Toyokuni, S., Itani, T., Morimitsu, Y., Okada, K., Ozeki, M., Kondo, S.Protective effect of colored rice over white rice on Fenton reaction-based renal lipid peroxidation in rats.Free Radical Research 2002; 36: 583-592.

5. Nam, S. H., Choi, S. P., Kang, M. Y., Koh, J. H., Kozukue, N., \& Friedman, M.

5. Antioxidative activities of bran extracts from twenty one pigmented rice cultivars. Food Chemistry 2006; 94: 613-620.

6. Yawadio, R., Tanimori, S., \& Morita, N Identification of phenolic compounds

6. isolated from pigmented rices and their aldose reductase inhibitory activities. Food Chemistry 2007; 101: 1616-1625.

7. McDougall GJ, Shpiro F, Dobson P, Smith P, Blake A, Stewart D. Different polyphenolic components of soft fruits inhibit alpha-amylase and alpha-glucosidase Journal of Agricultural and Food Chemistry 2005; 53: 2760-2766.

8. Sompong R, Ehn S, Martin L, Berghofer E. Physicochemical and antioxidant properties of red and black rice varieties from Thailand, China and Sri Lanka, Food Chemistry 2011; 124: 132-140.

9. Abdel-Aal, E. M., Young, J. C., and Rabalski, I. Anthocyanin composition in black, blue, pink, purple, and red cereal grains. Journal of Agricultural and Food Chemistry 2006; 54: 4696-4704.

10. Aguilar-Garcia, C., Gavino, G., Baragano-Mosqueda, M., Hevia, P. and Gavino, V.C. Correlation of tocopherol, tocotrienol, oryzanol and total polyphenol content in rice bran with different antioxidant capacity assays. Food Chemistry 2001; 102: 12281232.

11. Yoenyongbuddhagal, S. and Noomhorm, A. Effect of raw material preparation on ricevermicelli quality. Cereal Chemistry 2002; 54:534 - 539.

12. Noosuka, P., Hill, S.E., Farhat, I.A., Mitchel, J.R.and Pradipasena, P. Relationship between viscoelastic properties and starch structure in rice from Thailand. Starch starke 2005; 57(3 - 4): 587 - 598.

13. Juliano B O. A simplified assay for milled rice amylose. Cereal Science Today 1971; 16(4): 334-360.

14. Juliano, B.O. Criteria and test for rice grain. In: Juliano, B.O. Rice Chemistry and

14. Technology. St. Paul, Minn. (USA) American Association of Cereal Chemists Inc., 1985:443-513.

15. Association of Official Analytical Chemistry. Official Methods of Analysis. 18 th ed. Method 2002.2. Arlington VA

16. Gońi, I., L.García-Diz, E. Mañas, and F. Saura-Calixto. Analysis of resistant starch: a method for foods and food products. Food Chemistry 1996; 56-65. 
17. Patindol, J., Gu, X. and Wang, Y-J. Chemometric analysis of the gelatinization and pasting properties of long-grain rice starches in relation to fine structure. Starch/Starke 2009; 63: 3-11.

18. Wanida T., Pramuan S., Siriporn S. and Putaluk K. Phenolic compound analyzation of Thai pigmented rice. Journal of Food Science and Engineering 2012; 2: 484- 492.

19. Mi-Young Kang, Catherine W., Sang-Chul Le. Varietal difference in physicochemical properties of pigmented rice varieties. Journal of Crop Science and Biotechnology 2011; 14 (2):111-118.

20. Saikia S., Himjyoti D., Daizi S., Charu L.M. Quality characterization and extermination of phytochemical content capacity of aromatic pigmented and nonpigmented rice varieties. Food Research International 2012; 46: 334- 340.

21. Goffman, F. D., \& Bergman, C. J. Rice kernel phenolic content and its relation-ship with antiradical deficiency. Journal of the Science of Food and Agriculture 2004; $84: 1235-1240$.

22. Wang KM, Wu JG, Li G, Zhang DP, Yang ZW, Shi CH. Distribution of phytic acid and mineral elements in three indica rice (Oryza sativa L.) cultivars. Journal Cereal Science 2011; 54:116-121.

23. Mpofu A., Sapirstein H. D., Beta T. Genotype and environmental variation in phenolic content, phenolic acid composition, and antioxidant activity of hard spring wheat Journal Agricultural Food Chemistry 2006; 54: 1265-1270.

24. Miller, J.; Pang, E.; Bramall, L. Rice: a high or low glycemic index food. American Journal Clinical Nutrition 1992; 56: 1034-1036.

25. Frei, M.; Siddhuraju, P.; Becker, K. Studies on the in vitro starch digestibility and the glycemic index of six different indigenous rice cultivars from the Philippines. Food Chemistry 2003; 83:395-402.

26. Alonso, A.; Calixto, F.Delcour, J. Influence of botanical source and processing on formation of resistant starch type III. Cereal Chemistry 1998; 75: 802-804.

27. Linfeng W., Ya-Jane W. and Raymond P. Structures and Physicochemical Properties of Six Wild Rice Starches. Journal of Agricultural and Food Chemistry 2002; 50: 2695-2699.

28. Ruttikan Inpun. 2014. Study of glycemic index of rice and flour of indigenous Southern Thai rice: Sangyod Phatthalung. Master of Science Thesis, Prince of Songkla University, Thailand. $81 \mathrm{p}$. 